\title{
Temperature-dependent Evolution of the Oxidation
}

\section{State of Cobalt and Platinum in $\mathrm{Co}_{1-\mathrm{x}} \mathrm{Pt}_{\mathrm{x}}$ Clusters}

\section{under $\mathrm{H}_{2}$ and $\mathrm{CO}+\mathrm{H}_{2}$ Atmosphere}

Bing Yang, ${ }^{\$ a}$ Ghassan Khadra ${ }^{\$ d}$ Juliette Tuaillon-Combes, ${ }^{d}$ Eric Tyo, ${ }^{a}$ Michael J. Pellin, ${ }^{a}$

Benjamin Reinhart, ${ }^{b}$ Sönke Seifert, ${ }^{b}$ Xinqi Chen, ${ }^{e}$ Veronique Dupuis, ${ }^{*^{d}}$ Stefan Vajda ${ }^{* a, c, f, g}$

${ }^{a}$ Materials Science Division, ${ }^{b} \mathrm{X}$-ray Science Division, and ${ }^{\mathrm{c}}$ Nanoscience and Technology

Division, Argonne National Laboratory, Lemont, IL 60439, USA

${ }^{\mathrm{d}}$ Institut Lumière Matière, University Lyon \& CNRS, Villeurbanne cedex, 69622, France

${ }^{\mathrm{e}}$ Department of Mechanical Engineering, Northwestern University, Evanston, IL 60208, USA

${ }^{\mathrm{f}}$ Department of Chemical and Environmental Engineering, Yale University, New Haven, CT

06520, USA

${ }^{\mathrm{g}}$ Institute for Molecular Engineering, University of Chicago, Chicago, Illinois 60637, USA

${ }^{\$}$ These authors contributed equally to this work.

${ }^{*}$ Corresponding authors:

SV e-mail: vajda@anl.gov; phone: +1-630-252-8123

VD e-mail: veronique.dupuis@univ-lyon1.fr; phone: +33-472448071 


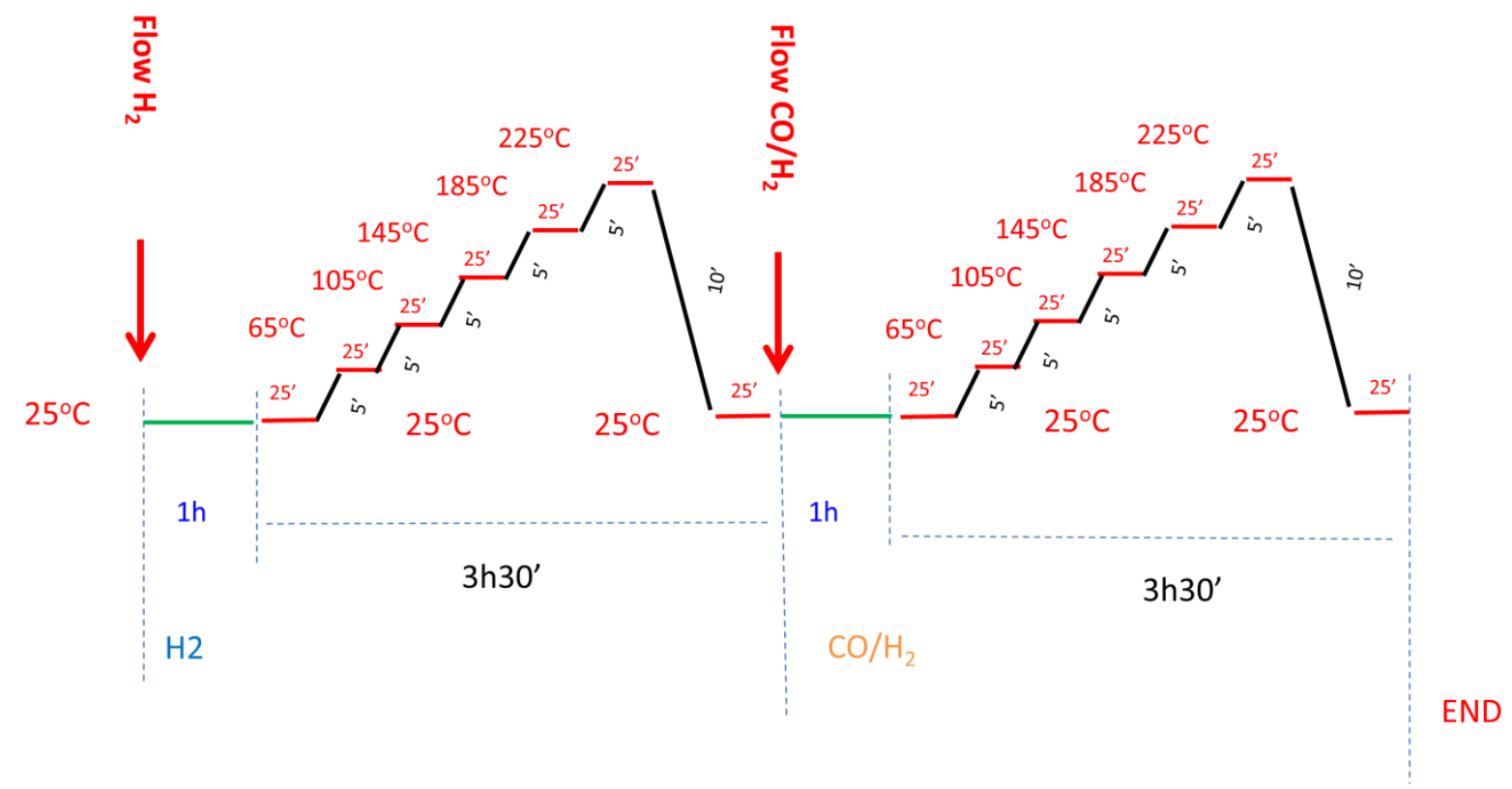

Figure S1. Double temperature ramp used in the in-situ GISAXS/GIXANES experiments. During the first ramp the $\mathrm{Co}_{1-\mathrm{x}} \mathrm{Pt}_{\mathrm{x}}$ samples were pretreated with $3.5 \% \mathrm{H}_{2}$ balanced He between 25 and $225{ }^{\circ} \mathrm{C}$ at 900 Torr, then subsequently, during the second ramp exposed to $1 \% \mathrm{CO}$ and $2 \% \mathrm{H}_{2}$ gas mixture balanced with He at temperatures between 25 and $225{ }^{\circ} \mathrm{C}$ under a pressure of 900 Torr. The heating rate between temperature steps was $8 \mathrm{~K} / \mathrm{min}$. Each time after switching the gas feed (from $\mathrm{He}$ to $\mathrm{H}_{2}$ to $\mathrm{CO}+\mathrm{H}_{2}$ ), the cell was purged with the new gas mixture for 1 hour (green line) at room temperature before the start of the collection of the in-situ GISAXS and GIXANES data. 


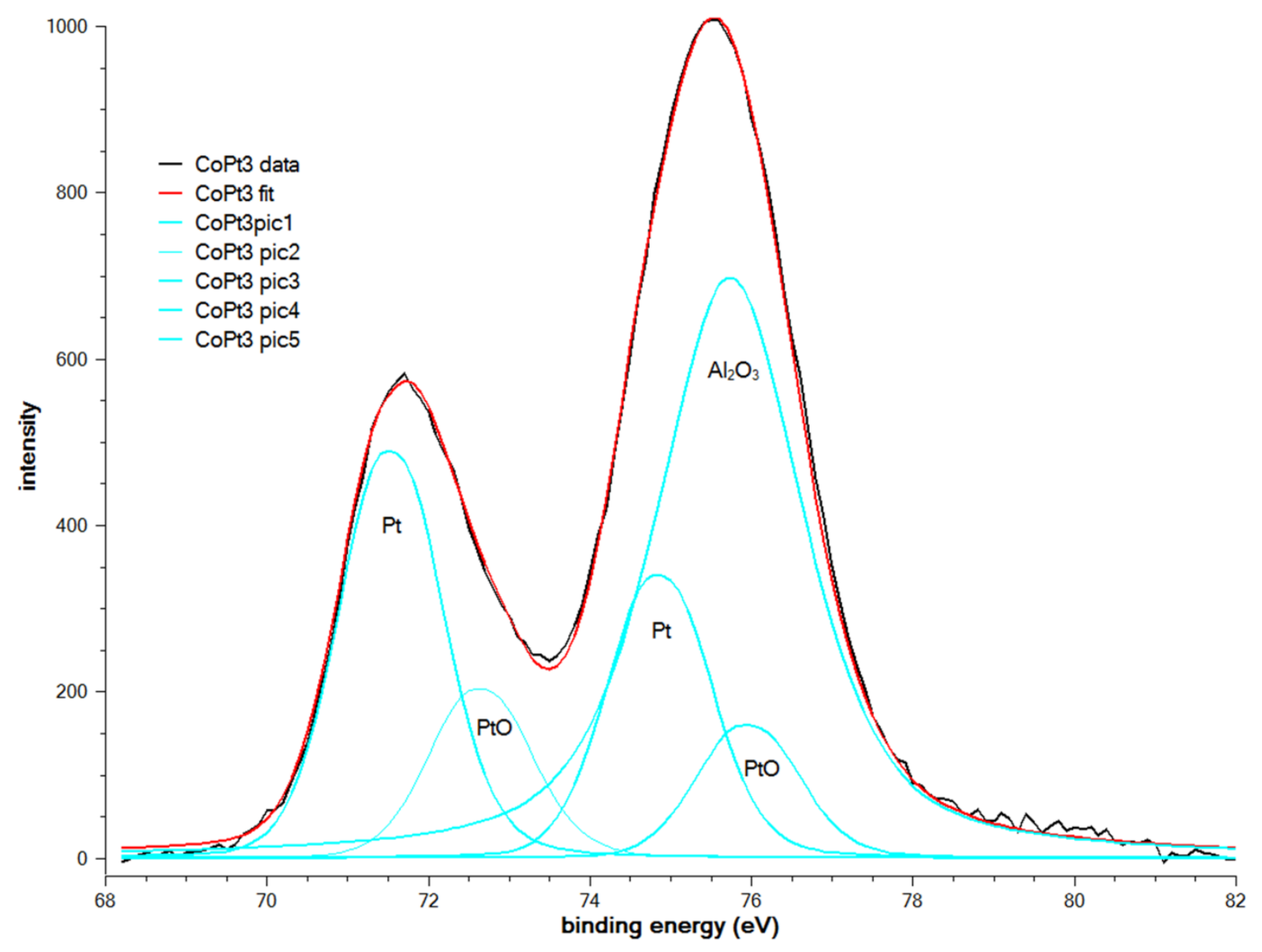

Figure S2. Example of XPS fitting on the as-made $\mathrm{Co}_{0.25} \mathrm{Pt}_{0.75}$ sample after an hour long exposure to air. The fitting results of Pt 4f core level reveals two components with Pt 4f 7/2 positioned at 70.67 and 71.76 $\mathrm{eV}$. The binding energy falls into the region of metallic $\mathrm{Pt}^{0}$ and $\mathrm{Pt}^{2+}$ oxide respectively. 

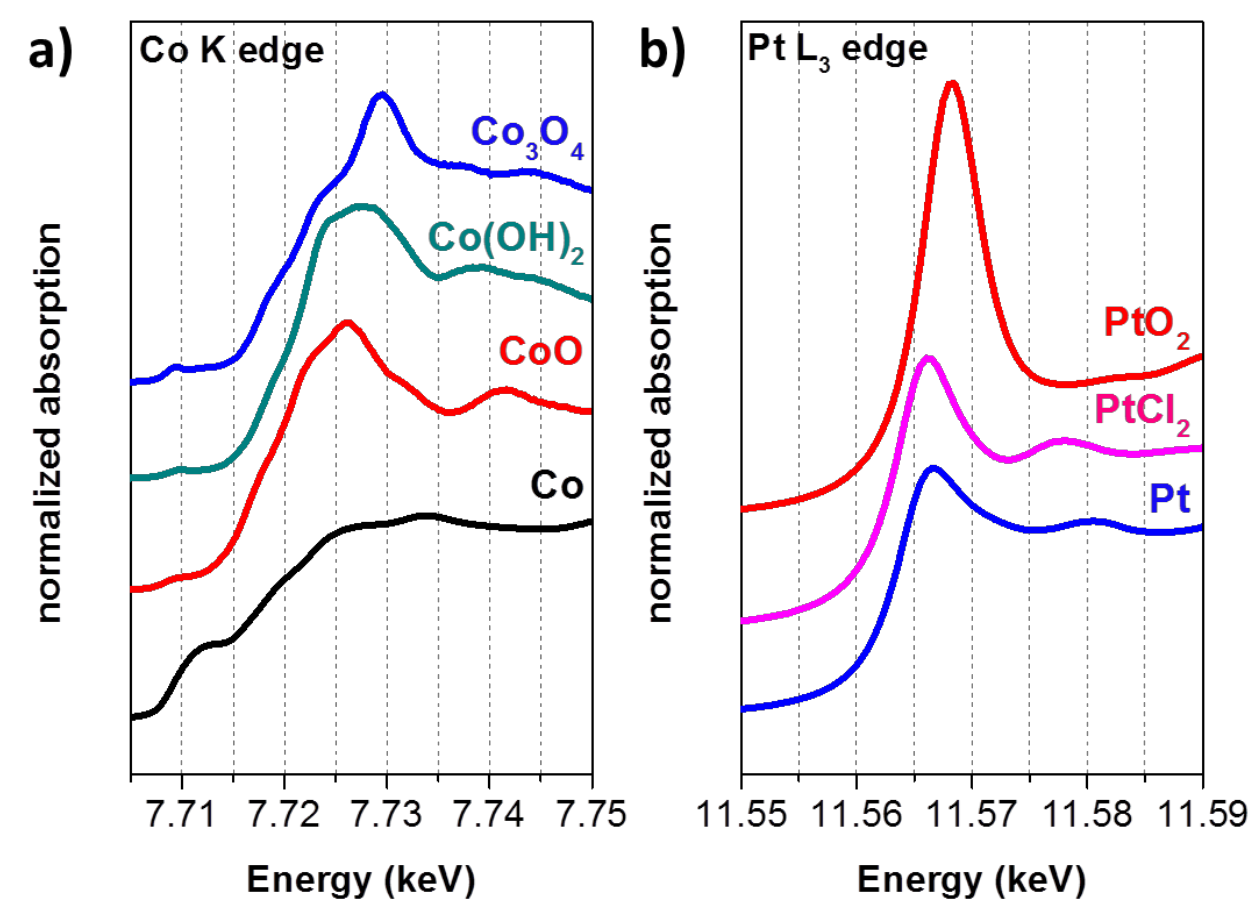

Figure S3 XANES spectra of reference macroscopic cobalt and platinum compounds: a) Co foil, CoO, $\mathrm{Co}(\mathrm{OH})_{2}$ and $\mathrm{Co}_{3} \mathrm{O}_{4}$; b) Pt foil, $\mathrm{PtCl}_{2}$ and $\mathrm{PtO}_{2}$. 

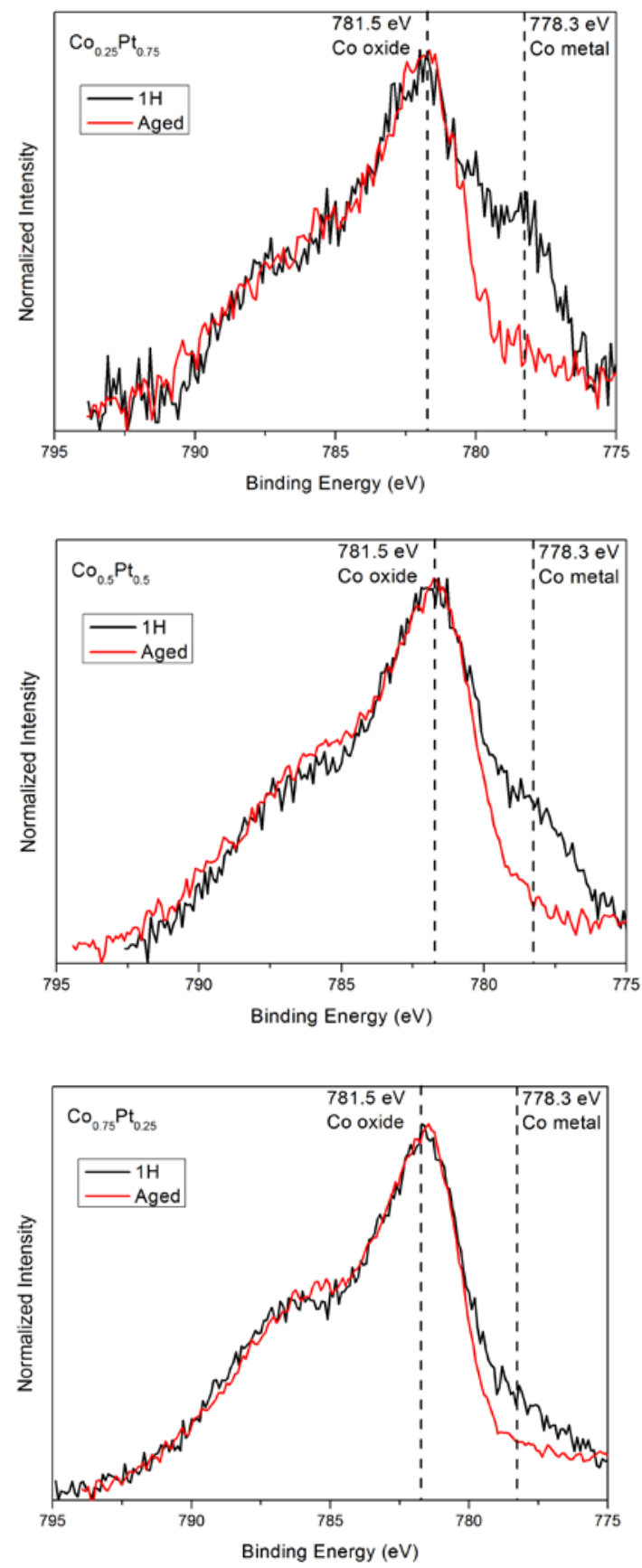

Figure S4. Normalized Co 2p spectra of as made mixed CoPt cluster samples after one hour exposure to the ambient (black line) and after aging (red line). The decreasing component of metallic Co can be clearly identified in the aged samples, which reflects the oxidation of the Co component after aging in air. 
a)

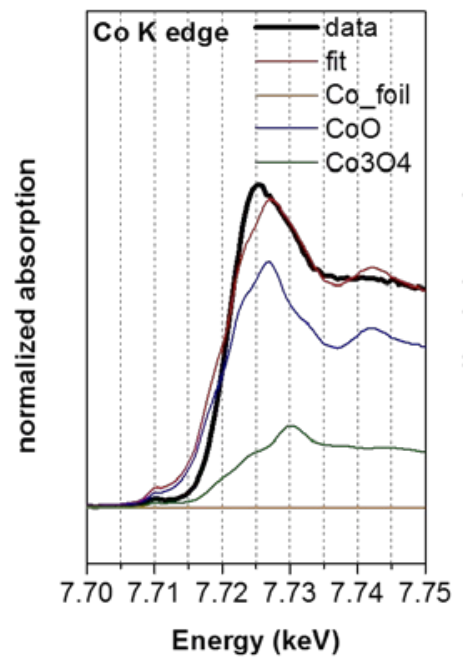

b)

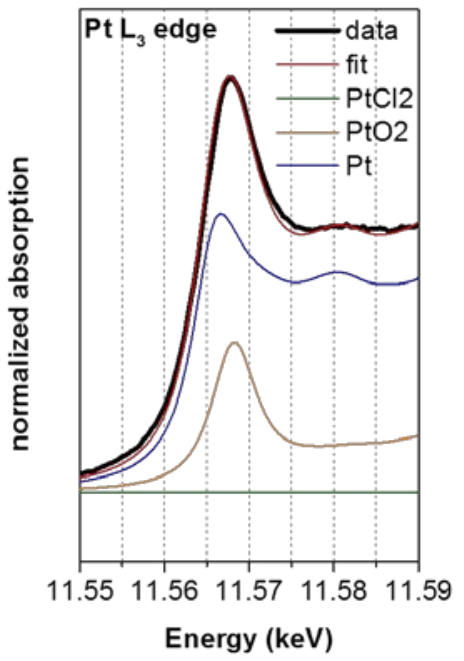

Figure S5. Plots showing typical results of linear combination fit of XANES spectra on the example of aged $\mathrm{Co}_{0.75} \mathrm{Pt}_{0.25}$ clusters a) Co K-edge: The measured spectrum, the resulting fit and individual Co components of the fit are shown. (R factor=0.007895) b) $\mathrm{Pt}_{3_{3}}$ edge: The measured spectrum, the resulting fit and individual Pt components are presented. (R factor=0.000647) We note that the deviations in spectral features, in comparison with those of the bulk standards, can be assigned to the size and (electronic and geometric) structure effects observed for small clusters and/or to alloying/dealloying, which are reflected as the sum of the absorption cross-section contributions from all sites in the particle with different valences and coordination.(See for example in Peters, S. et al.” Inner-shell photoionization spectroscopy on deposited metal clusters using soft x-ray synchrotron radiation: An experimental setup.” Rev. Sci. Instrum. 80, 125106 (2009); Yin et al in "Size and Support Dependent Evolution of the Oxidation State and Structure by Oxidation of Subnanometer Cobalt Clusters”, J. Phys. Chem. A 118, 8477-8484 (2014); Bartling et al in "Pronounced Size Dependence in Structural and Morphological Transitions of Gas-Phase Produced and Partially Oxidized Co Nanoparticles under Catalytic Reaction Conditions”, ACS Nano 9, 5984-5998, (2015),; and Y.S. Lee et al, “XPS core-level shifts and XANES studies of Cu-Pt and Co-Pt alloys”. Surf. Interface Anal. 2000, 30, 475) 

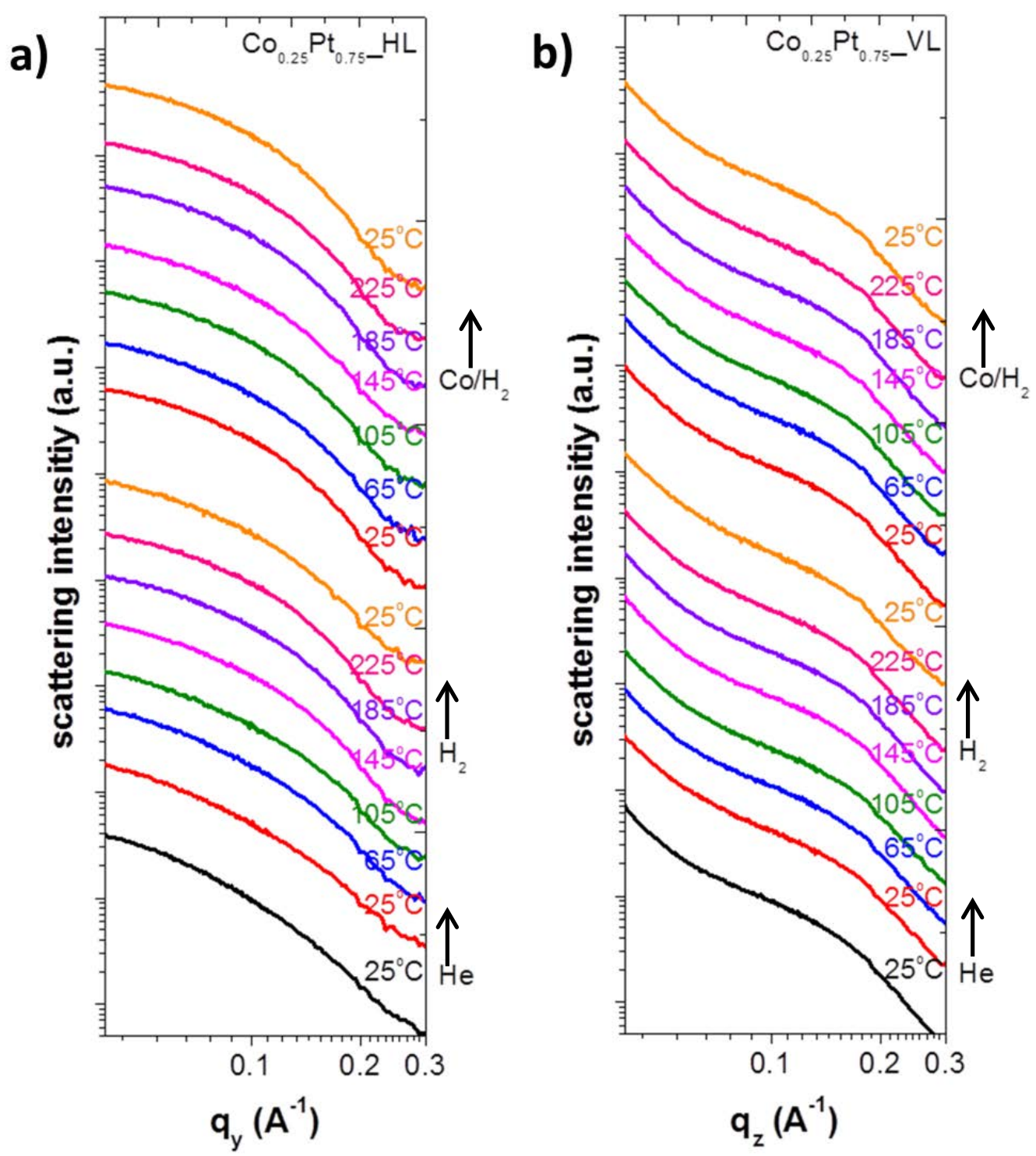

Figure S6. Horizontal (a) and vertical (b) cuts of typical in situ GISAXS data, obtained on $\mathrm{Co}_{0.25} \mathrm{Pt}_{0.75}$ clusters. From the bottom to the top: data collected under helium at room temperature, under hydrogen between 25 and $225{ }^{\circ} \mathrm{C}$ and under $\mathrm{CO}$ and hydrogen mixture between 25 and $225^{\circ} \mathrm{C}$ (see Figure S1 for the details on the temperature ram and reaction conditions. The unchanged horizontal (a) and vertical (b) cuts indicate that the clusters are stable in their size and shape under these temperature and gas chemical conditions. 
a)

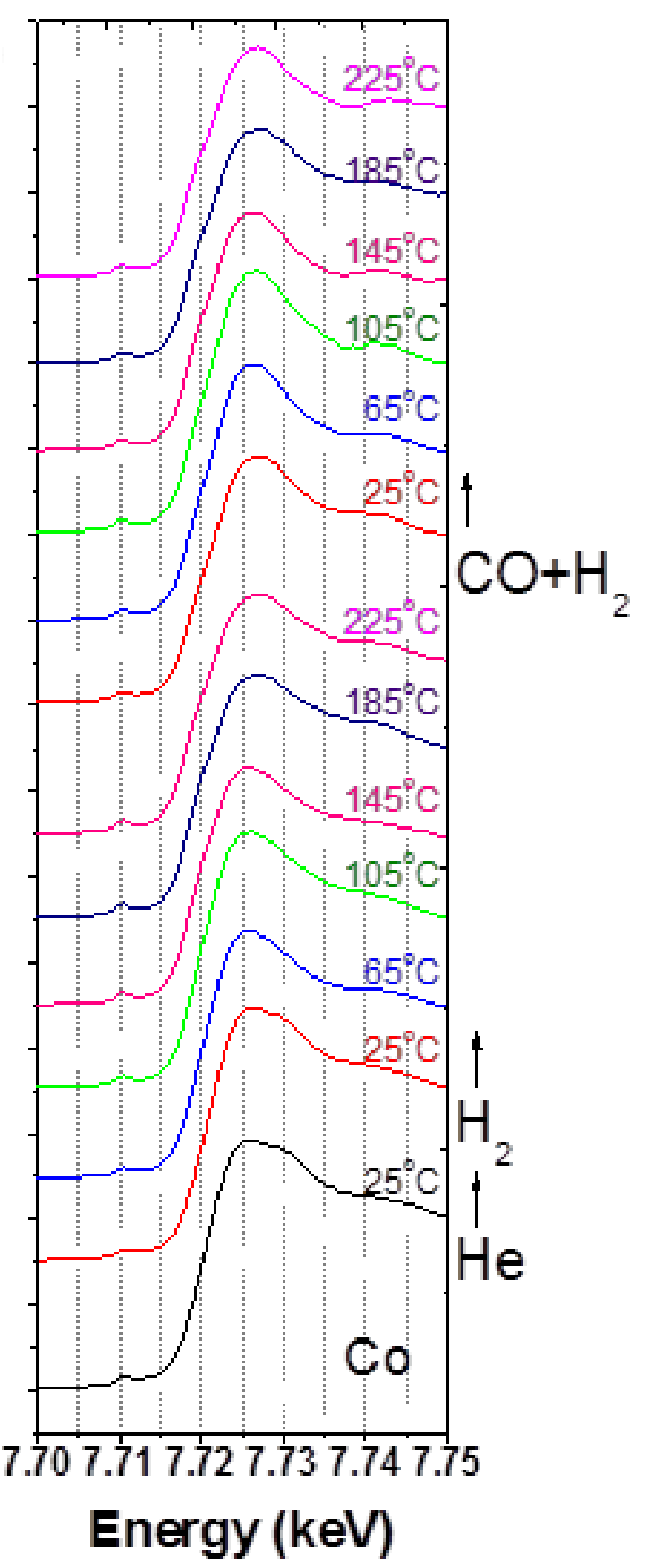

b)

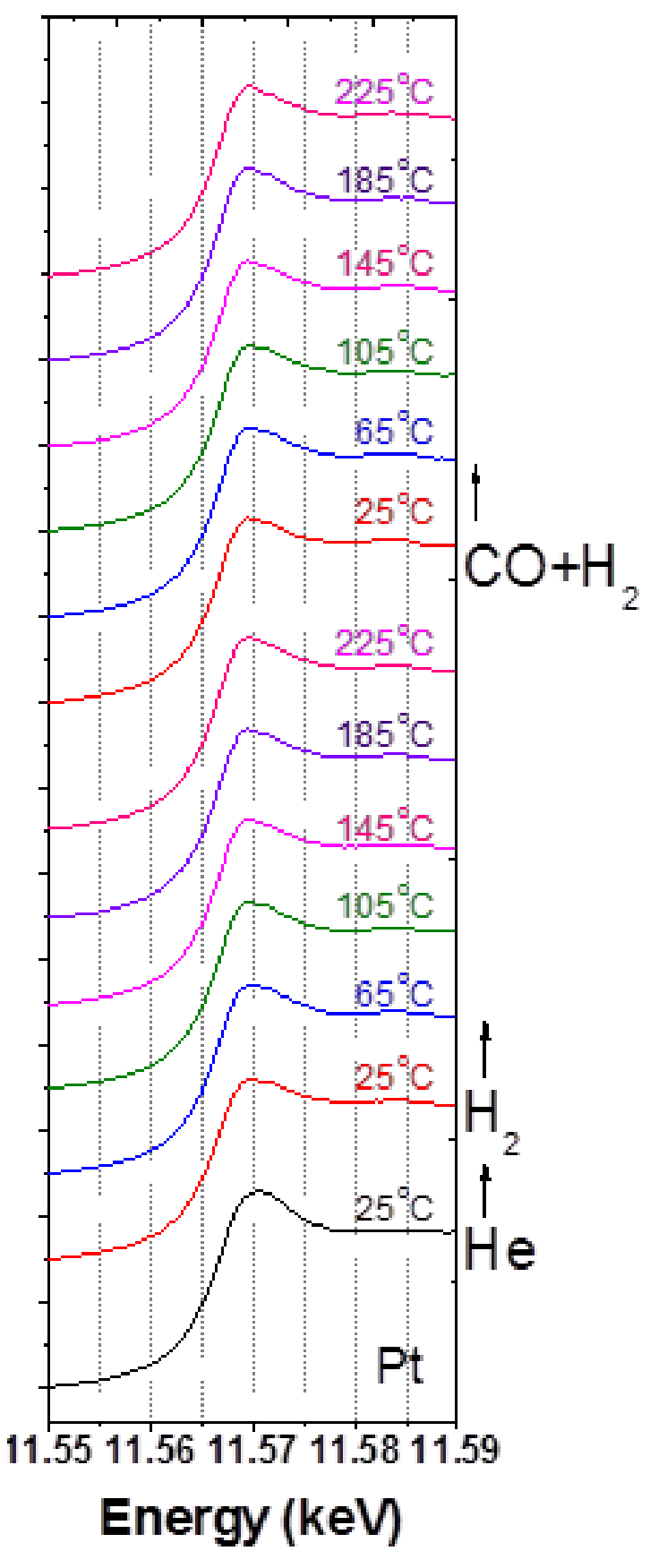

Figure S7. In situ XANES data collected on monometallic Co (a) and Pt (b) clusters, at the Co K-edge and $\mathrm{Pt}_{3}$-edge, respectively under $\mathrm{He}, \mathrm{H}_{2}$ and $\mathrm{CO}+\mathrm{H}_{2}$ from $25^{\circ} \mathrm{C}$ to $225^{\circ} \mathrm{C}$. (See Figure S1 for the details of the applied experimental conditions.) 


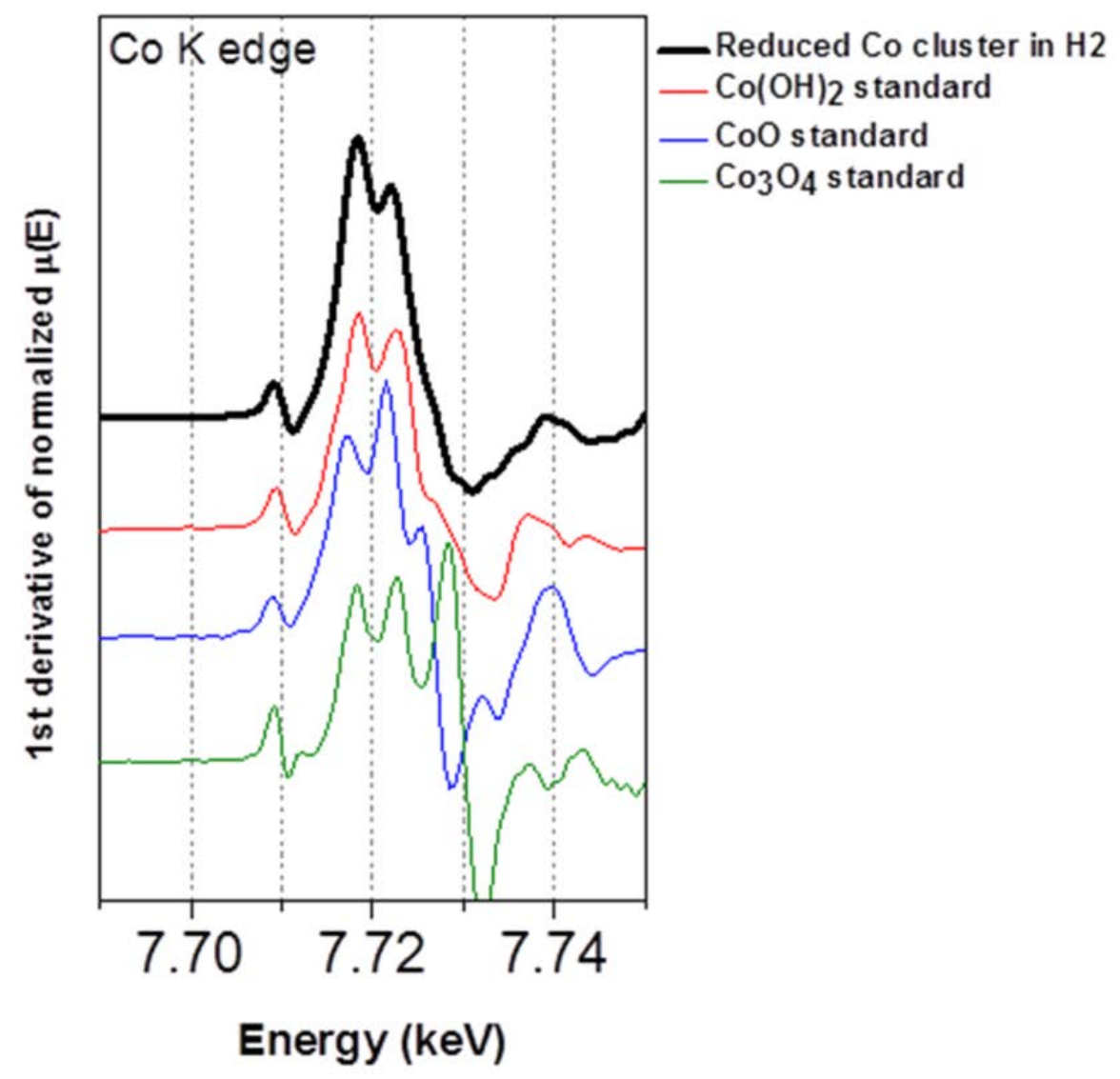

Figure S8. The $1^{\text {st }}$ derivative XANES feature of monometallic Co clusters under in-situ $\mathrm{H}_{2}$ pretreatment at $185^{\circ} \mathrm{C}$, as well as the reference $1^{\text {st }}$ derivative spectra of $\mathrm{Co}(\mathrm{OH})_{2}, \mathrm{CoO}$ and $\mathrm{Co}_{3} \mathrm{O}_{4}$ standards. 
a)

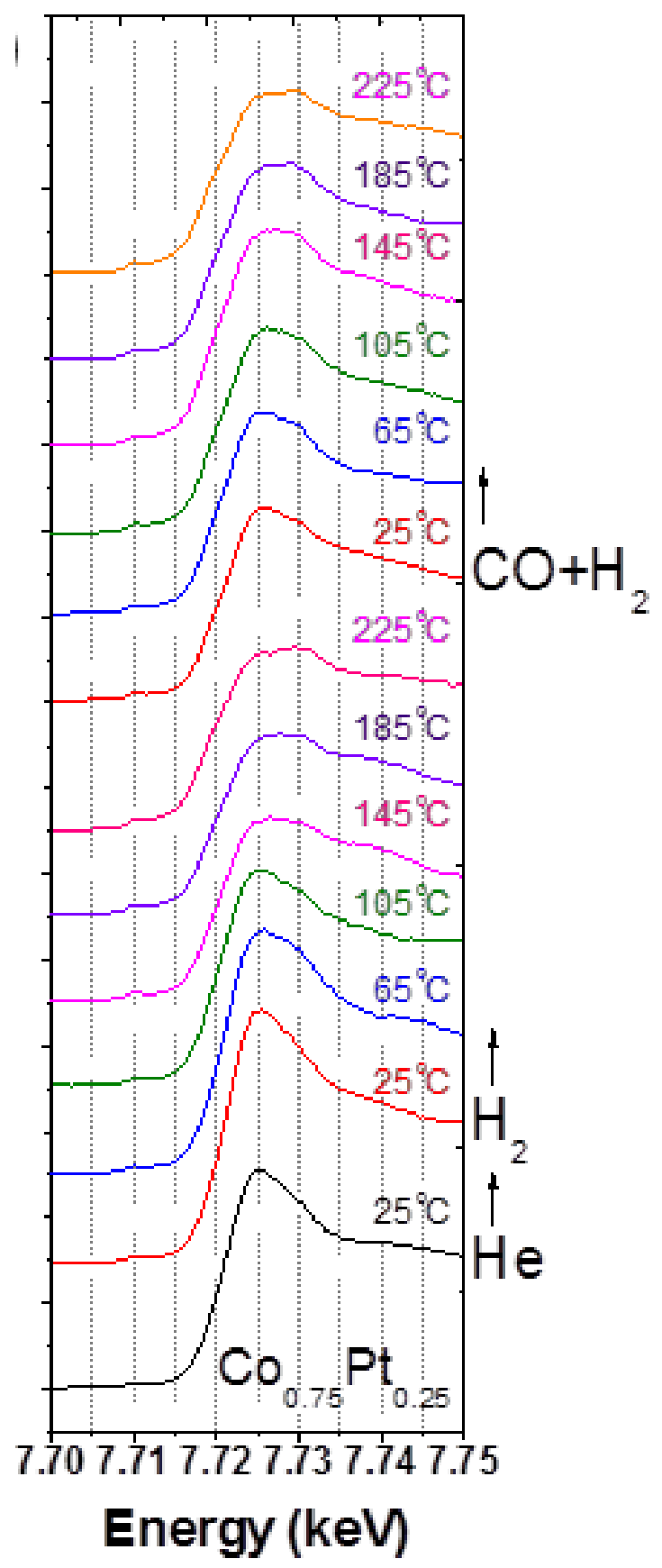

b)

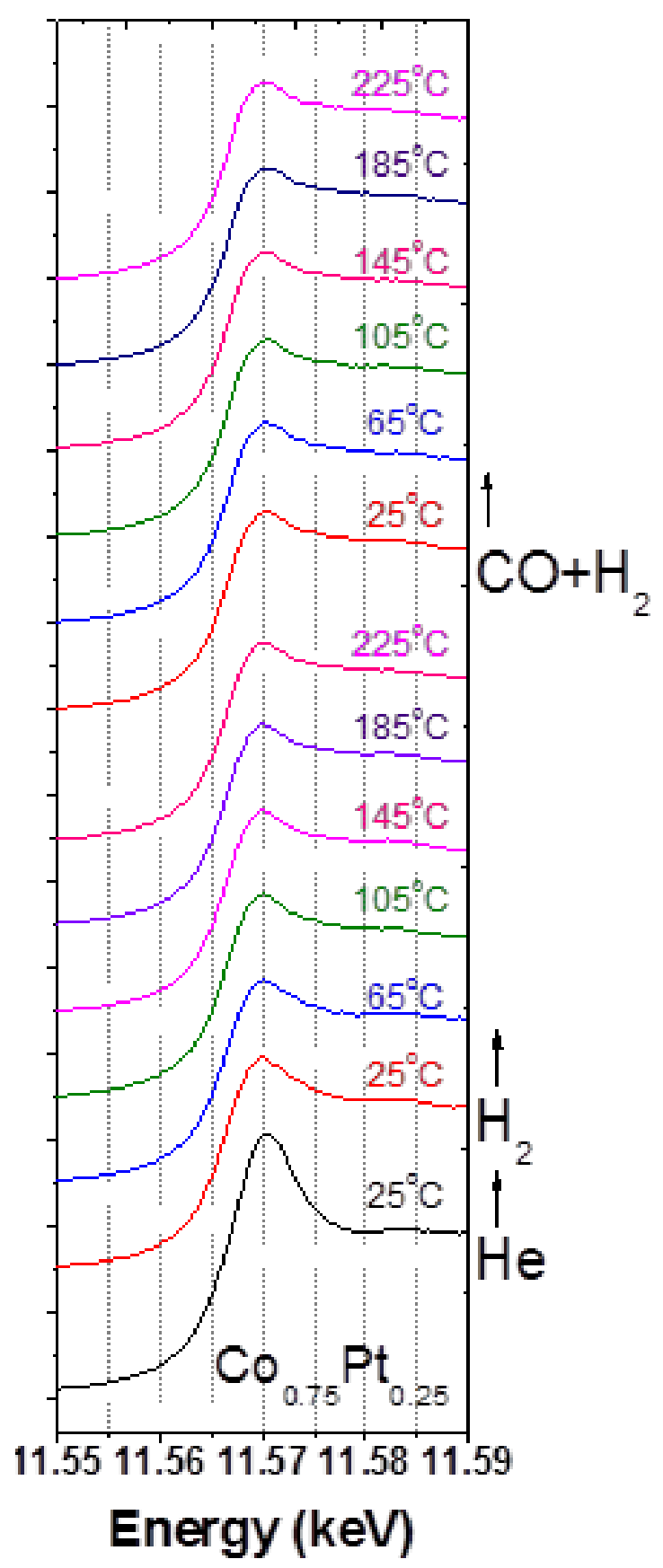

Figure S9. In situ XANES data collected on $\mathrm{Co}_{0.75} \mathrm{Pt}_{0.25}$ clusters, at the Co K-edge (a) and $\mathrm{Pt} \mathrm{L}_{3^{-}}$ edge (b), respectively under $\mathrm{He}, \mathrm{H}_{2}$ and $\mathrm{CO}+\mathrm{H}_{2}$ from $25^{\circ} \mathrm{C}$ to $225^{\circ} \mathrm{C}$. (See Figure $\mathrm{S} 1$ for the details of the experimental conditions.) 
a)

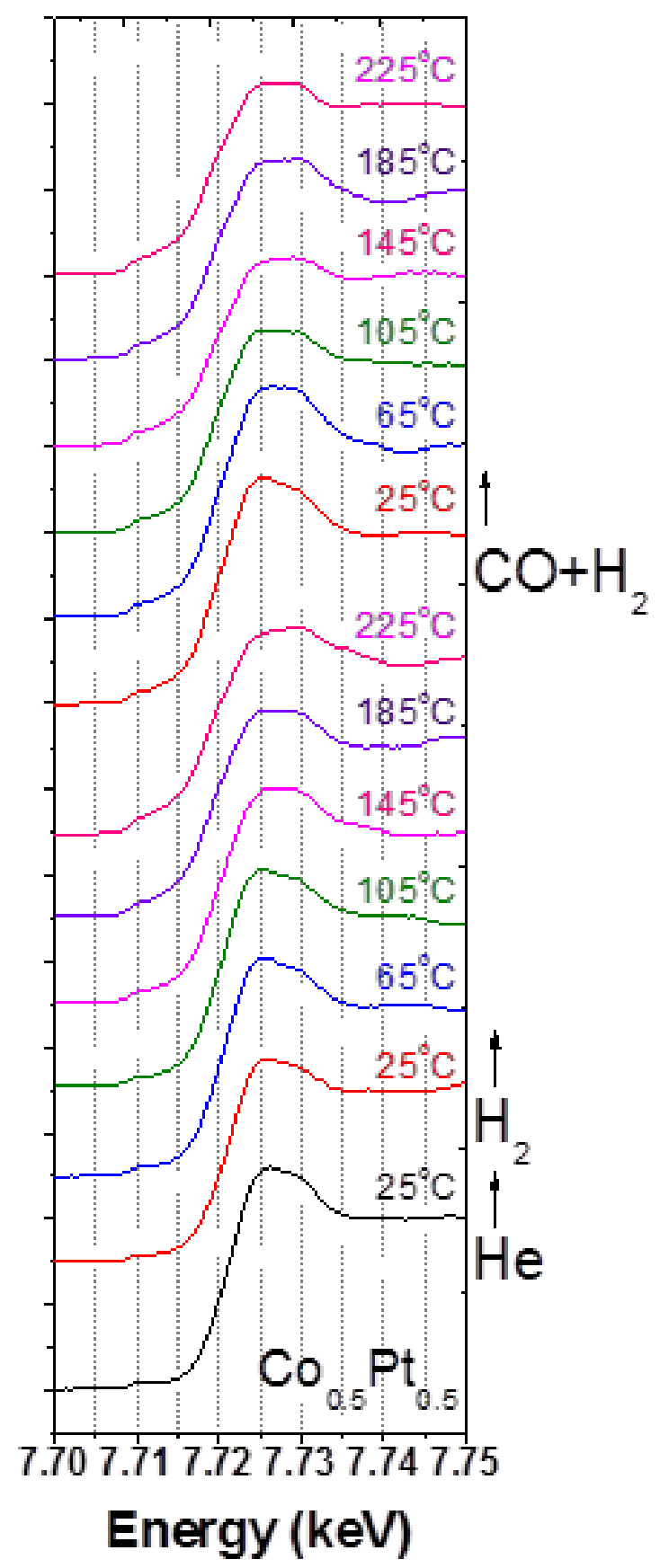

b)

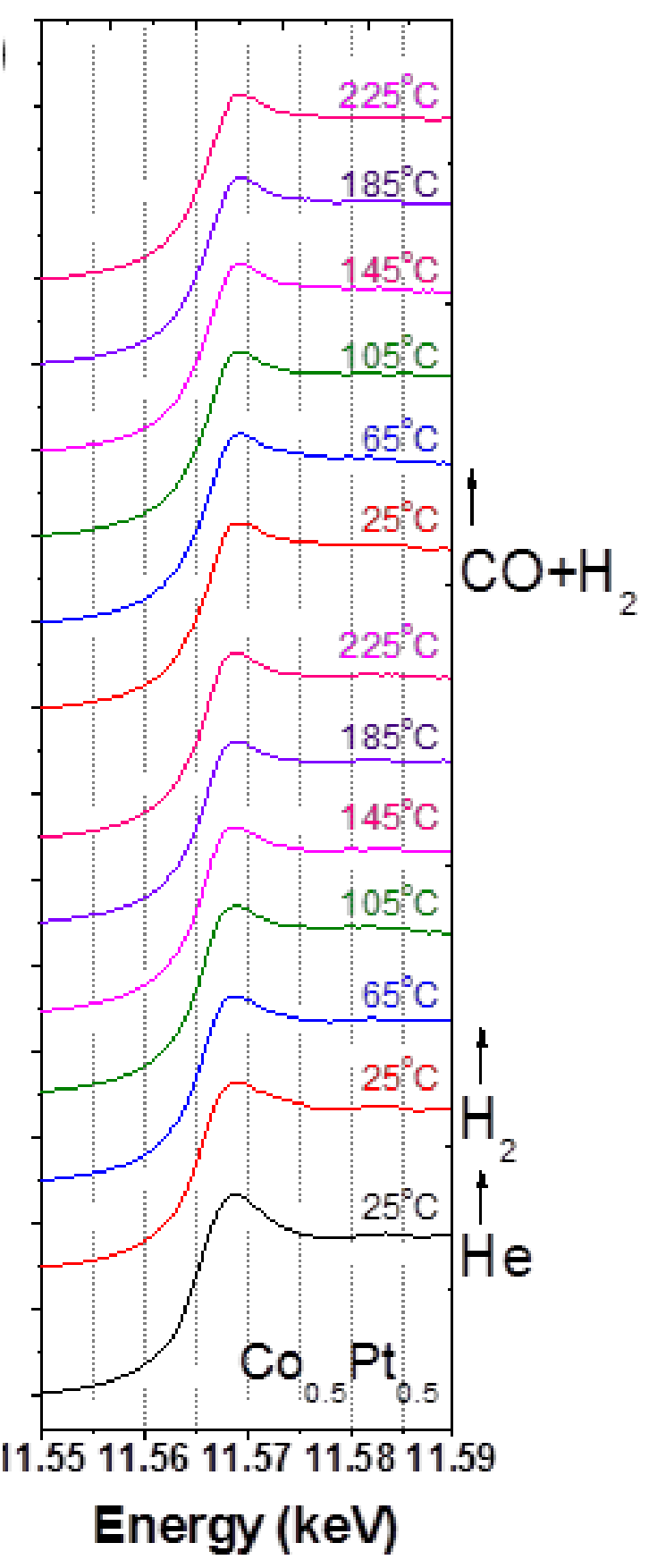

Figure S10. In situ XANES data collected on $\mathrm{Co}_{0.50} \mathrm{Pt}_{0.50}$ clusters, at the Co K-edge (a) and Pt $\mathrm{L}_{3}$-edge (b), respectively under $\mathrm{He}, \mathrm{H}_{2}$ and $\mathrm{CO}+\mathrm{H}_{2}$ from $25^{\circ} \mathrm{C}$ to $225^{\circ} \mathrm{C}$. (See Figure $\mathrm{S} 1$ for the details of the experimental conditions.) 
a)

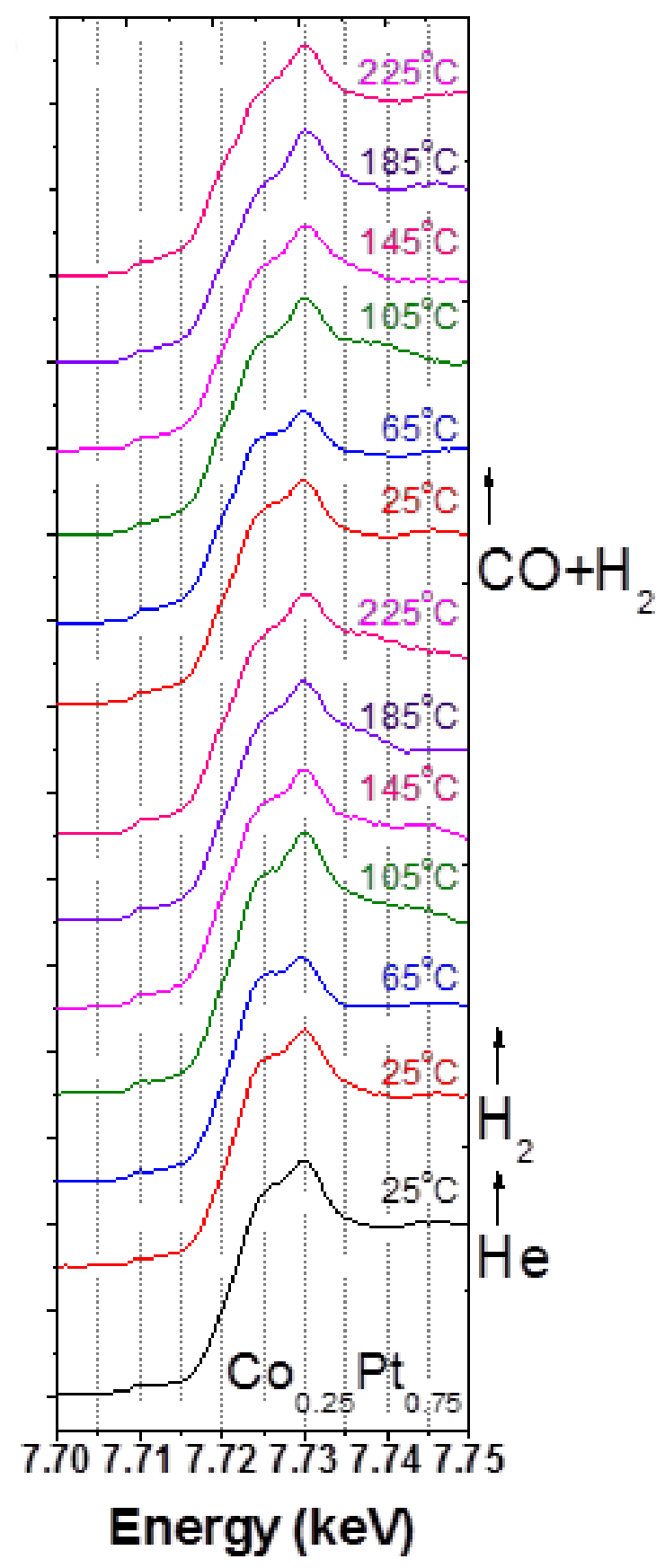

b)

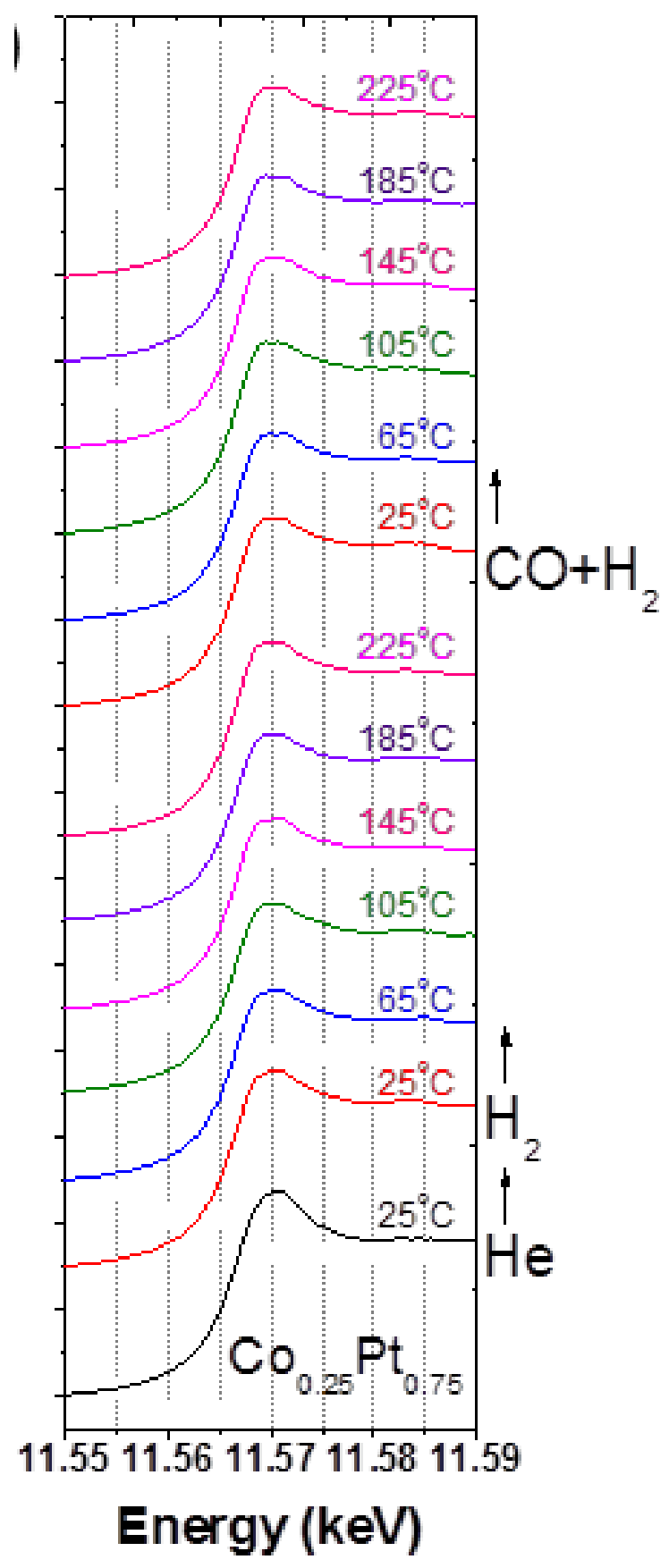

Figure S11. In situ XANES data collected on $\mathrm{Co}_{0.25} \mathrm{Pt}_{0.25}$ clusters, at the Co K-edge (a) and Pt $\mathrm{L}_{3}$-edge (b), respectively under $\mathrm{He}, \mathrm{H}_{2}$ and $\mathrm{CO}+\mathrm{H}_{2}$ from $25^{\circ} \mathrm{C}$ to $225^{\circ} \mathrm{C}$. (See Figure $\mathrm{S} 1$ for the details of the experimental conditions.) 
Table S1. Relative concentration of $\mathrm{Pt}$ and $\mathrm{Pt}^{2+}$ oxide for as-made $\mathrm{Co}_{1-\mathrm{x}} \mathrm{Pt}_{\mathrm{x}}$ bimetallic clusters. The error is 0.1-0.2 eV for the binding energy and 5\% for the relative concentration of Pt/PtO.

\begin{tabular}{lcccc}
\hline Sample & \% Pt & Energy (eV) & \% $\mathbf{P t}^{2+}$ Oxide & Energy (eV) \\
\hline $\mathbf{P t}$ & $70 \pm 5$ & 70.5 & $30 \pm 5$ & 71.61 \\
$\mathbf{C o}_{0.25} \mathbf{P t}_{\mathbf{0 . 5}}$ & $70 \pm 5$ & 70.67 & $30 \pm 5$ & 71.76 \\
$\mathbf{C o}_{0.5} \mathbf{P t}_{\mathbf{0 . 5}}$ & $62 \pm 5$ & 70.51 & $38 \pm 5$ & 71.57 \\
$\mathbf{C o}_{\mathbf{0 . 7 5}} \mathbf{P t}_{\mathbf{0 . 2 5}}$ & $57 \pm 5$ & 70.7 & $43 \pm 5$ & 71.68 \\
\hline
\end{tabular}

